\title{
Relationship between Pore Structure and Chloride Ion Diffusivity in Cementitious Materials
}

\author{
Yuya Sakai \\ Institute of Industrial Science, The University of Tokyo, 4-6-1 Komaba, Meguro, Tokyo 153-8505, \\ Japan \\ ysakai@iis.u-tokyo.ac.jp
}

Abstract: In this study, literature on pore structure and chloride ion diffusivity was collected to investigate the correlation of pore structure indicators with diffusivity. Good correlation between total porosity and chloride ion diffusivity was found when the samples did not contain admixture materials and diffusion test was conducted without acceleration. Pore diameter indicators did not correlate with diffusivity. The diffusivity of cement paste was reduced by admixture materials compared to that without admixture materials even if the total porosity is the same. On the other hand, the diffusivity of concrete was not reduced by admixture materials.

Keywords: cementitious material, pore structure, chloride ion, diffusivity, admixture material

Highlights:

- Total porosity correlates with diffusivity without admixture and acceleration

- Pore diameter indicators did not correlate with diffusivity

- The diffusivity of cement paste was reduced by admixture but not in concrete

- Diffusivity from accelerated test was smaller than that from non-accelerated test

\section{Introduction}

Chloride ion is one of the most important deterioration factors of concrete structures [1]; therefore, the evaluation and prediction of chloride ion diffusion into concrete is essential for the estimation of durability and lifetime of concrete structures. One of the problems in the evaluation of chloride ion penetration into concrete by diffusion is the long duration of the experiment. To shorten the experimental time, methods to accelerate chloride ion penetration have been developed $[2,3]$ and some researchers reported good correlation between the diffusion coefficients measured with and without acceleration $[4,5]$. However, the relationship has not been clarified and there is no agreed equation to convert the diffusivity obtained in accelerated test to that without accelerated test. Furthermore, the experimental time is not short enough. To further decrease the experimental time, a higher voltage is necessary; however, this results in heat generation [6]. To solve this problem, it is desired to convert a 
property of concrete to diffusivity. One possible approach is to establish a relationship between chloride ion diffusivity and pore structure in concrete and estimate the diffusion coefficient from the pore structure. Chloride ion transport can be evaluated from the pore structure as chloride ion moves through pore network in concrete. Some numerical simulations have been carried out to estimate the mechanical and durability performance of concrete [7, 8]. In these simulations, the pore structure of cementitious material was simulated using parameters such as mixing design and curing condition, and a relationship between chloride ion diffusivity and pore structure should be established to estimate the resistance from the obtained pore structure against chloride ion penetration.

Many studies have investigated the relationship between chloride ion diffusion and pore structure. However, it is unclear which indicator of pore structure is suitable for estimating chloride ion diffusivity. Caré [9], Higashiyama [10] and Luna et al. [11] reported that there is a correlation between chloride ion diffusivity and total porosity. On the other hand, Halamickova et al. [12], Mohammed et al. [13], Schiessl and Wiens [14] and Moon et al. [15] reported that diffusivity correlates with critical pore diameter, threshold pore diameter and average pore diameter, respectively. Therefore, it is clear that various indicators of pore structure have been reported to have good correlation with chloride ion diffusivity because the number of data items used in these studies was limited. As a result, it is still unclear which indicator of pore structure has a clear correlation with chloride ion diffusivity.

In this study, literature that measured both chloride ion diffusivity and pore structure was collected to discuss which indicator of pore structure is suitable for estimating chloride ion diffusivity. If an indicator of pore structure has a strong correlation with diffusivity, chloride ion diffusivity can be evaluated from pore structure obtained in experiments or numerical simulation. This will also enable us to estimate diffusivity from a small concrete sample or even concrete pieces, which is not possible in diffusivity test. Furthermore, in the penetration test of chloride ion, the effect of heat generated by electrical potential difference was concerned [6], and this effect was verified by estimating the diffusivity from pore structure to validate the accuracy of the experiment.

\section{Review of literature}

In this study, literature that reported on both pore structure and chloride ion diffusivity was collected and analysed. Many authors reported only the differentiated curve of pore size distribution or few pore structure indicators. However, this study aims to determine which pore structure indicator is suitable for estimating chloride ion diffusivity. Therefore, literature that reported both the cumulative and the derivative of pore size distribution was collected to determine all the necessary pore structure indicators. However, even if either the cumulative or derivative pore size distribution is missing in any article, it can be included if the intrusion steps are clear; the missing item is obtained by converting from the available item. Table 1 lists the literature used in this study. Ferreira et al. [16] and Zhang and 
Zhao [17] reported the derivative of pore size distribution and the intrusion steps were shown; however, each plot was not clear because there are many plots. Therefore, these were omitted in this study. He et al. [18] reported on cumulative curves of pore size distribution; however, their data were also omitted in this study owing to inconsistency in the names of specimens in the figure and those in the text. Diffusion test on cracked specimens [19] or diffusion test during loading [20, 21] were omitted to meet the objective of this study. Furthermore, data from concrete exposed to marine environment [22] were not included.

Table 1 Literature collected for chloride ion diffusivity and pore structure indicators

\begin{tabular}{|l|l|l|l|l|}
\hline \multirow{2}{*}{ Authors } & \multicolumn{2}{c|}{ Sample } & \multicolumn{2}{c|}{ Chloride } \\
\cline { 2 - 5 } & \multicolumn{1}{|c|}{ Type } & \multicolumn{1}{c|}{ Admixture } & \multicolumn{1}{c|}{ Test Condition } & \multicolumn{1}{c|}{ Measured } \\
\hline Caré [9] & Paste & \multicolumn{1}{c|}{-} & Natural & Depth \\
\hline Du and Pang [23] & Mortar & Graphene nanoplatelet & Natural & Distribution \& depth \\
\hline Filho et al. [6] & Concrete & FA and hydrated lime & Accelerated & Depth \\
\hline Isfahani et al. [24] & Concrete & Nano silica & Natural & Distribution \\
\hline Luna et al. [11] & Concrete & BFS and LP & Natural & Distribution \\
\hline Mohammed et al. [13] & Concrete & LP, FA and silica fume & Accelerated & Depth \\
\hline Moon et al. [15] & Concrete & BFS & Accelerated & Depth \\
\hline Ribeiro et al. [25] & Concrete & Red mud & Accelerated & Concentration \\
\hline Sun et al. [26] & Paste, mortar & & Accelerated & Concentration \\
\hline Touil et al. [27] & Concrete & Natural pozzolan & Accelerated & Concentration \\
\hline Yang et al. [28] & Concrete & Nano composites & Accelerated & Depth \\
\hline
\end{tabular}

FA: Fly ash, BFS: Blast furnace slag, LP: Lime stone powder

It can be observed from Table 1 that most studies investigated concrete; however, cement paste and mortar were also included. The admixture materials include fly ash, blast furnace slag, clay and nano composites. Mohammed et al. [13] used a self-compacting concrete sample. In terms of the experimental method, some studies used natural (non-accelerated) diffusion driven by the concentration gradient, whereas others used accelerated diffusion by applying electrical potential difference. In terms of evaluation, some studies measured the penetration depth of chloride ion (indicated as "depth" in Table 1), some measured the concentration of the solution ("concentration") and others measured the chloride ion distribution in concrete ("distribution"). We reviewed literature that reported both chloride diffusivity in non-accelerated condition and total porosity, even if the pore size distribution was not reported in the literature, as listed in Table 2. Data reported by Jen et al. [29] were not used because the samples for diffusivity and porosity were not consistent; chloride ion diffusivity was measured in mortar but total porosity was measured in cement paste. 
Table 2 Literature collected for chloride ion diffusivity and total porosity

\begin{tabular}{|l|l|l|l|}
\hline \multirow{2}{*}{\multicolumn{1}{|c|}{ Authors }} & \multicolumn{2}{c|}{ Sample } & \multirow{2}{*}{ Measured } \\
\cline { 2 - 4 } & \multicolumn{1}{|c|}{ Type } & \multicolumn{1}{c|}{ Admixture } & \\
\hline Kikuchi et al. [30] & Cement paste & FA, BFS and silica fume & Concentration \\
\hline Kurumisawa and Nawa [31] & Cement paste & - & Depth \\
\hline Mihara et al. [32] & Cement paste & \multicolumn{1}{|c|}{-} & Distribution \\
\hline Nwaubani [33] & Cement paste & Fuel ash and meta-kaolin & Concentration \\
\hline Saeki et al. [34] & Concrete & FA, BFS & Concentration \\
\hline
\end{tabular}

FA: Fly ash, BFS: Blast furnace slag

\section{Methodology}

In this study, chloride ion diffusivity and pore structure were obtained from collected literature and the relationship between diffusivity and pore structure indicators was established. Pore structure indicators, such as total porosity, median pore diameter, critical pore diameter and threshold pore diameter obtained through mercury intrusion porosimetry (MIP) were examined. The total porosity is defined as the maximum cumulative volume of intruded mercury, the median pore diameter is defined as the corresponding pore diameter when the volume of intruded mercury reaches half the total porosity, and the critical pore diameter is defined as the corresponding pore diameter when the derivative of the pore size distribution reaches the maximum [35]. There are several definitions for the threshold pore diameter as reported in [36]; however, it is defined in this paper as the intersection between the tangent of the sudden intrusion part and the abscissa axis.

\section{Results and discussions}

Fig. 1 shows a comparison of chloride ion diffusivity and pore structure indicators. Ribeiro et al. [25] and Du and Pang [23] reported diffusivities measured using two methods and both results were plotted. From the report by Caré [9], only the data for uncracked samples were used. All the indicators correlate minimally with chloride ion diffusivity. A possible reason is the change in resistance against chloride ion penetration and immobilization of chloride ion due to admixture materials [37-39]. In Fig. 2, different markers were used for data with and without admixtures. Here, admixture materials include pozzolana material such as fly ash, blast furnace slag, silica fume and natural pozzolana. Data with admixture materials have slightly smaller chloride ion diffusivity. In terms of total porosity, data without admixture materials tend to positively correlate with chloride ion diffusivity, whereas data with admixture materials did not correlate with chloride ion diffusivity. Previous studies reported that 
water permeability and air permeability of cementitious material clearly correlate with the pore size regardless of the admixture material $[40,41]$. This indicates that the factor governing chloride ion transfer in cementitious materials is different from that of air and liquid. Another possible reason is the difference in the experimental condition, with and without acceleration. In Fig. 3, different markers were used for data with and without acceleration. The chloride ion diffusivity values measured without acceleration were larger compared to those obtained from accelerated test. This trend is opposite that reported by Chiang and Yang [5], which indicates that conversion of data obtained by accelerated diffusion test to that of natural diffusion test is not straight forward. Data from natural diffusion test correlate positively with chloride ion diffusivity, whereas there is no clear correlation or even negative correlation exists between data from accelerated diffusion test and chloride ion diffusivity. 
- Caré [9]

Isfahani et al. [24]

Moon et al. [15]

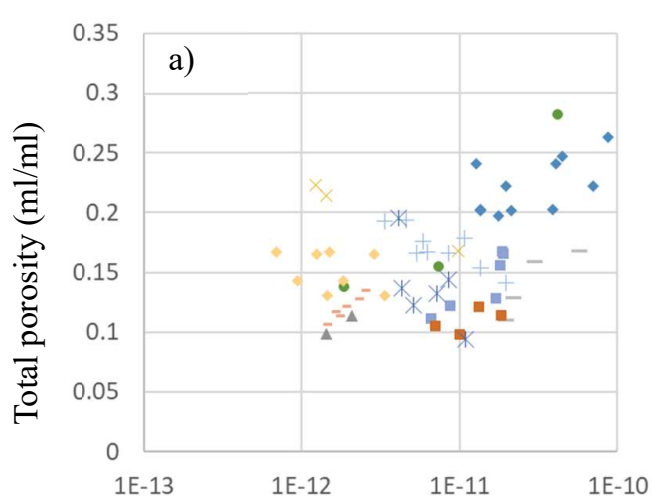

Chloride ion diffusion coefficient $\left(\mathrm{m}^{2} / \mathrm{s}\right)$

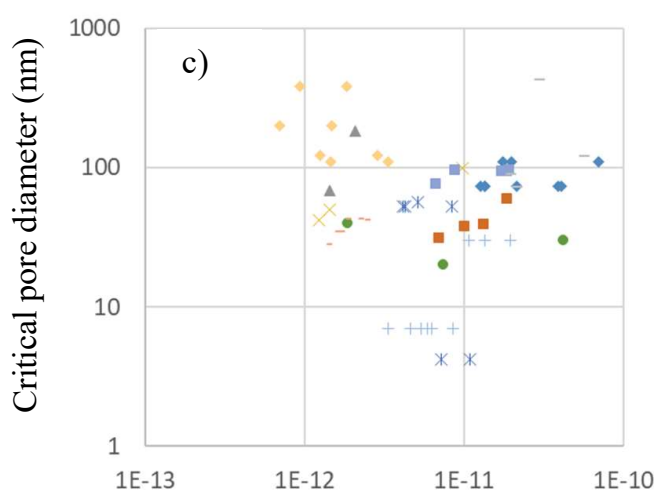

Chloride ion diffusion coefficient $\left(\mathrm{m}^{2} / \mathrm{s}\right)$
- Du and Pang [23]

- Luna et al. [11]

Ribeiro et al. [25]
Filho et al. [6]

- Mohammed et al. [13]

* Sun et al. [26]

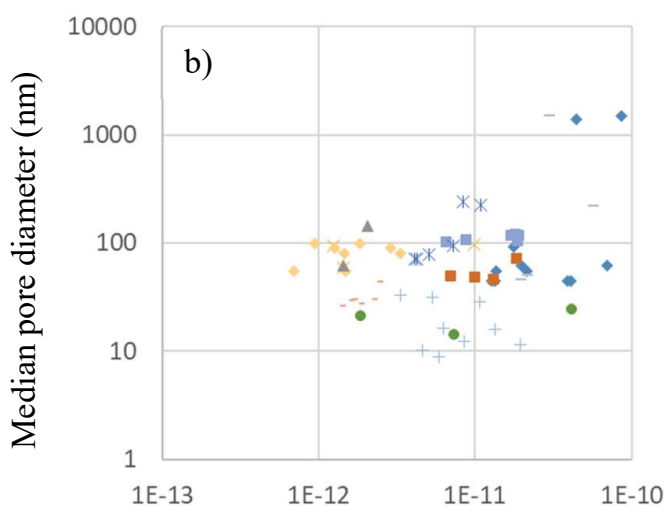

Chloride ion diffusion coefficient $\left(\mathrm{m}^{2} / \mathrm{s}\right)$

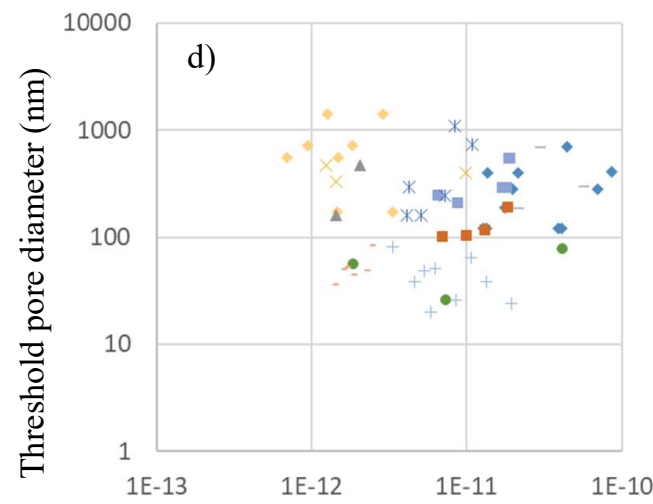

Chloride ion diffusion coefficient $\left(\mathrm{m}^{2} / \mathrm{s}\right)$

Figure 1 Relationship between chloride ion diffusion coefficient and pore structure indicators: a) total porosity, b) median pore diameter, c) critical pore diameter, and d) threshold pore diameter 


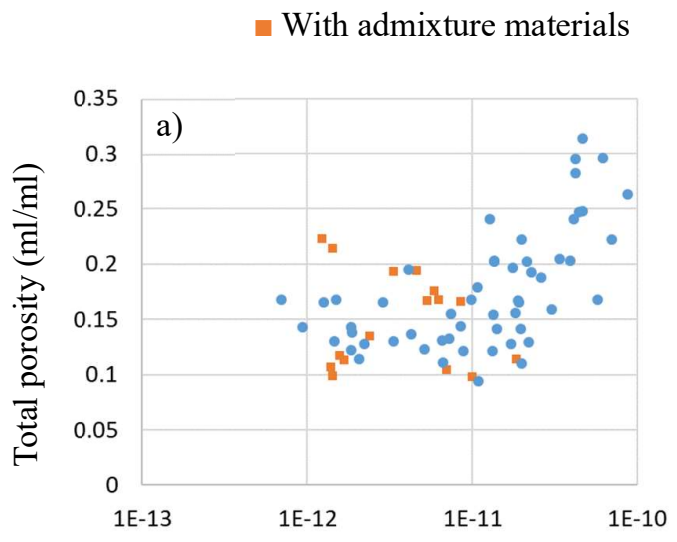

Chloride ion diffusion coefficient $\left(\mathrm{m}^{2} / \mathrm{s}\right)$

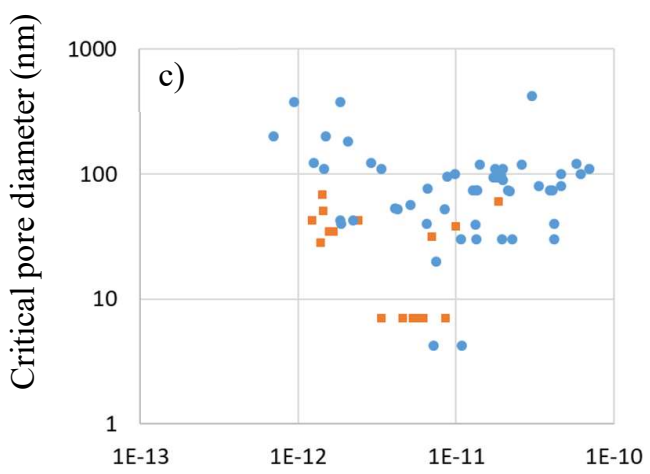

Chloride ion diffusion coefficient $\left(\mathrm{m}^{2} / \mathrm{s}\right)$
- Without admixture materials

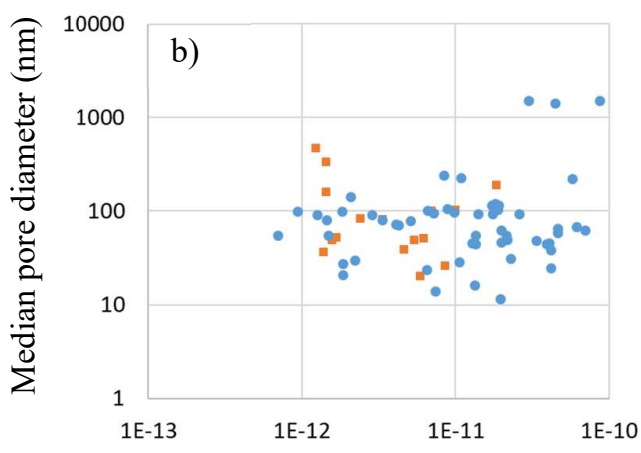

Chloride ion diffusion coefficient $\left(\mathrm{m}^{2} / \mathrm{s}\right)$

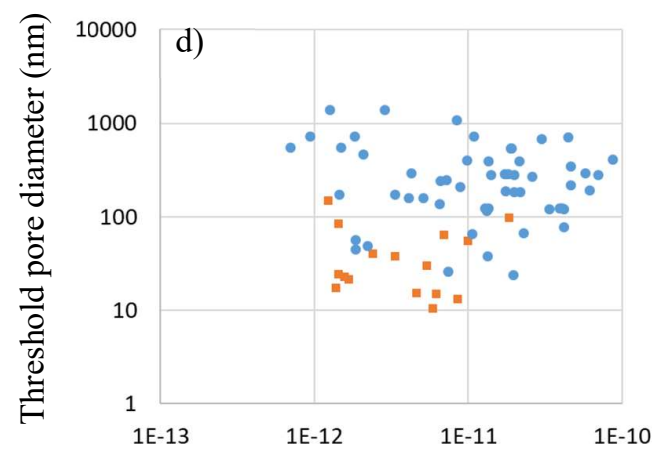

Chloride ion diffusion coefficient $\left(\mathrm{m}^{2} / \mathrm{s}\right)$

Figure 2 Relationship between chloride ion diffusion coefficient and pore structure indicators of samples with and without admixture materials: a) total porosity, b) median pore diameter, c) critical pore diameter, and d) threshold pore diameter 


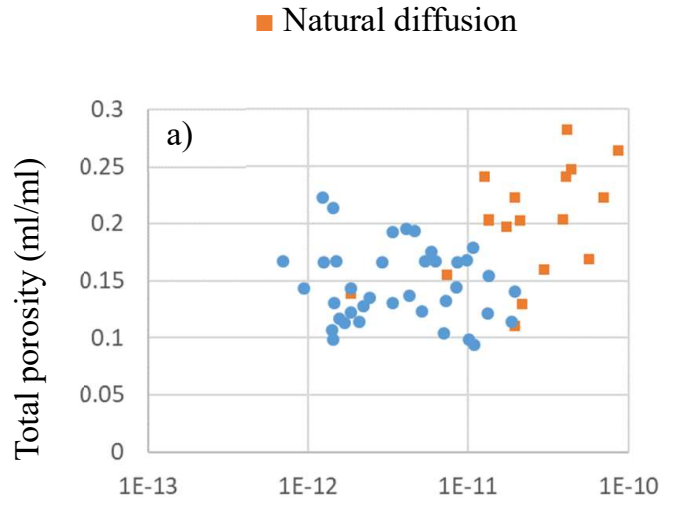

Chloride ion diffusion coefficient $\left(\mathrm{m}^{2} / \mathrm{s}\right)$

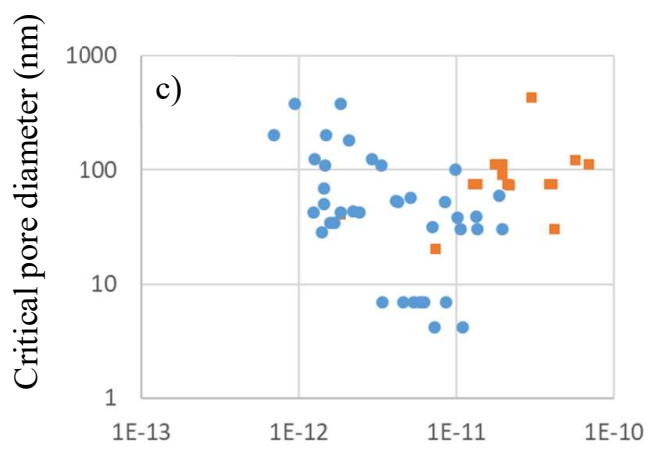

Chloride ion diffusion coefficient $\left(\mathrm{m}^{2} / \mathrm{s}\right)$

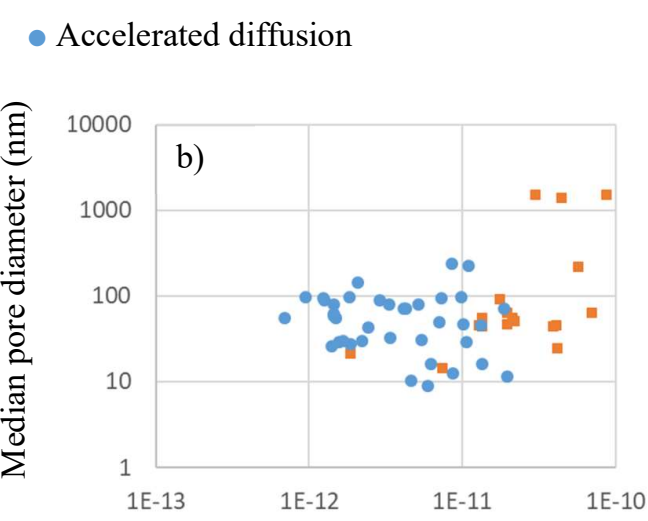

Chloride ion diffusion coefficient $\left(\mathrm{m}^{2} / \mathrm{s}\right)$

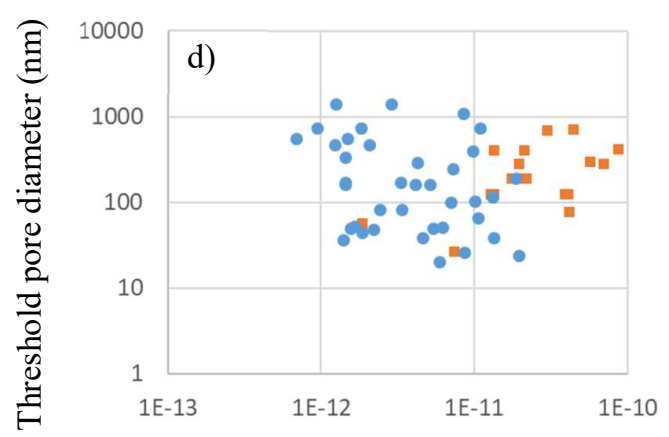

Chloride ion diffusion coefficient $\left(\mathrm{m}^{2} / \mathrm{s}\right)$

Figure 3 Relationship between measured chloride ion diffusion coefficient with and without acceleration and pore structure indicators: a) total porosity, b) median pore diameter, c) critical pore diameter, and d) threshold pore diameter

The total porosity obtained with natural diffusion test and no admixture materials positively correlate with chloride ion diffusivity. Furthermore, more studies investigated both chloride ion diffusivity and total porosity compared to those that investigated pore diameter indicators. Therefore, as a next step, studies (Table 2) that measured the total porosity and chloride ion diffusivity without acceleration were reviewed, even if pore size distribution was not investigated. The results are plotted in Fig. 4, but no clear correlation can be observed. Here, the result of concrete and cement paste should be separated owing to inconsistency in the tests on concrete; the effect of gravel was included in the diffusion test but not in the total porosity measurement with MIP because the pore structure is generally analysed after removing gravel from the concrete sample. Fig. 5 shows data for cement paste and concrete in which different markers were used for with and without admixture materials. The two lines in the 
figure are the regression curves of data without admixture materials assuming logarithmic approximation. We found that the total porosity correlates with chloride ion diffusivity of cement paste and concrete without admixture materials, with determination coefficients of 0.61 and 0.79 , respectively. The equations of the regression curves are as follows:

Cement paste: Chloride ion diffusivity $=10^{-13} e^{38 \times(\text { total porosity) }}$

Concrete: Chloride ion diffusivity $=10^{-12} e^{6.8 \times(\text { total porosity })}$

The data in these figures include the diffusivity calculated by measuring chloride ion penetration depth and solution concentration. This indicate that the effect of the different measuring items is not significant. In terms of cement paste (Fig. 5a)), all the data with admixture materials have lower diffusivity values compared to those without admixture materials, even if the total porosity is similar. On the other hand, in concrete, we observed some reduced diffusivity values with admixture materials but there was no difference in some diffusivity values or even larger diffusivity values were observed compared to diffusivity values without admixture materials. These results indicate that in natural diffusion, or in a realistic diffusion condition, the reduction of chloride ion diffusivity due to admixture material is noticeable in cement paste compared to concrete. The reason for this behaviour is unclear; however, possible reasons are that cement paste has a larger volume for the immobilization of chloride ion due to admixture material and admixture materials can change the surface potential of cement paste [42], and resistance against chloride ion due to electric action is more effective in cement paste because there is no interfacial transition zone unlike in concrete. The above results indicate that to reduce chloride ion penetration, reducing the total porosity may be more effective than reducing the pore diameter, unlike in air and liquid penetration [40,41]. Future study should investigate other factors to be considered other than total porosity in evaluating chloride ion diffusivity to determine the dominant factor for chloride diffusivity in cementitious materials. 


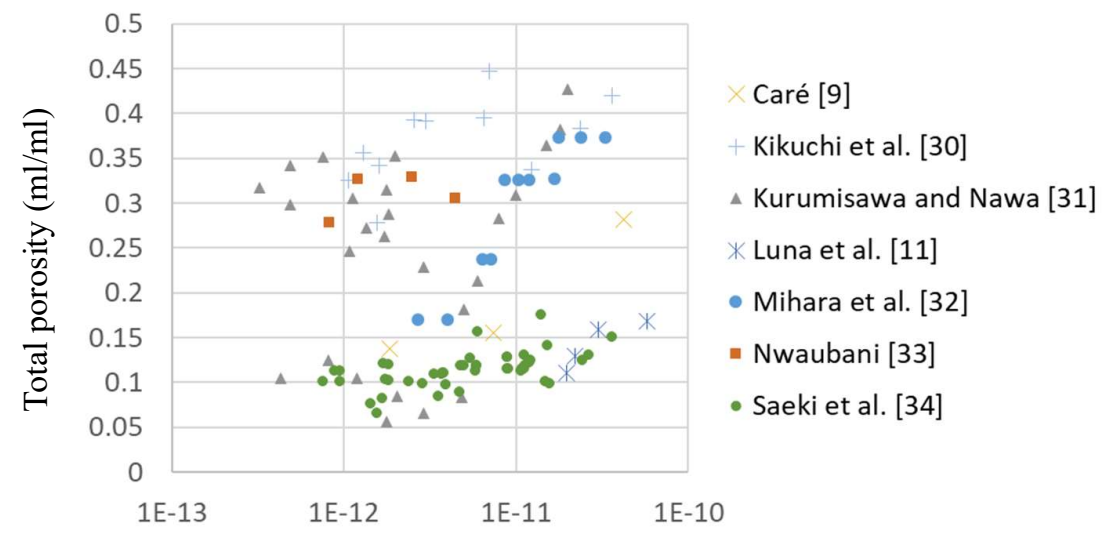

Chloride ion diffusion coefficient $\left(\mathrm{m}^{2} / \mathrm{s}\right)$

Figure 4 Relationship between chloride ion diffusion coefficient measured with natural diffusion test and total porosity

n Without admixture materials - With admixture materials

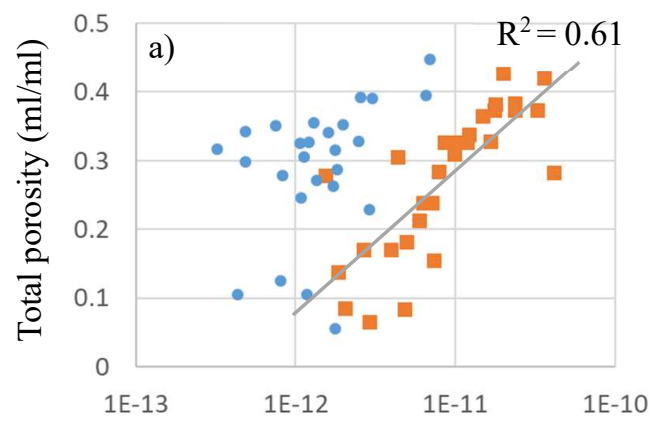

Chloride ion diffusion coefficient $\left(\mathrm{m}^{2} / \mathrm{s}\right)$

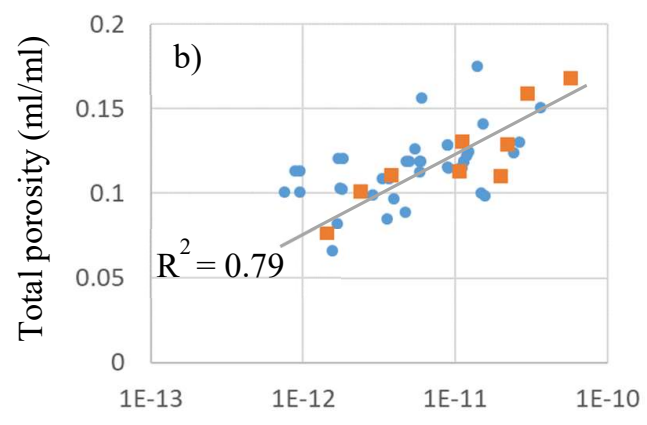

Chloride ion diffusion coefficient $\left(\mathrm{m}^{2} / \mathrm{s}\right)$

Figure 5 Relationship between chloride ion diffusion coefficient measured without acceleration and total porosity: a) cement paste and b) concrete

\section{Conclusion}

In this study, the relationship between the indicators of pore structure and chloride ion diffusivity in cementitious materials was investigated and we found a good correlation between total porosity and diffusivity when the sample did not include admixture materials and the diffusion test was conducted without acceleration. This result indicates that the diffusivity of chloride ion is governed by a different mechanism than air and liquid transfer, which correlates highly with the indicator of the pore diameter 
in a previous study. The natural diffusivity of cement paste and concrete without admixture materials can be estimated using the equations presented in this paper. The reduction of diffusivity due to admixture materials was significant in cement paste but not in concrete, which indicates that the evaluation of the effect of admixture material using cement paste may result in the underestimation of diffusivity if the result is applied to concrete. The diffusivity value obtained from accelerated test was smaller compared to the value obtained from natural diffusion test. This indicates that the use of accelerated test may result in the underestimation of diffusivity. Natural diffusion test should be conducted on concrete specimens to evaluate chloride ion diffusivity. This study revealed not only the relationship between total porosity and chloride ion diffusivity, but also the appropriate test condition for the evaluation of diffusivity. In the future, factors that determine the derivation of data with and without admixture material and other factors to be considered other than total porosity in evaluating chloride ion diffusivity to improve the accuracy of diffusivity estimation without conducting diffusion test.

Acknowledgement: This study was supported by JSPS KAKENHI grant number 18K13809.

Declarations of interest: None.

References

[1] A.M. Neville, Properties of Concrete 5th Edition, Trans-Atlantic Publications, Inc2012.

[2] ASTM C 1202-91, Standard Test Method for Electrical Indication of Concrete's Ability to Resist Chloride Ion Penetration, American Society for Testing and Materials, 1991.

[3] NT BUILD 492, Chloride migration coefficient from non-steady state migration experiments, NORTEST, 1999.

[4] P. Spiesz, H.J.H. Brouwers, The apparent and effective chloride migration coefficients obtained in migration tests, Cement and Concrete Research 48 (2013) 116-127.

[5] C.T. Chiang, C.C. Yang, Relation between the diffusion characteristic of concrete from salt ponding test and accelerated chloride migration test, Materials Chemistry and Physics 106(2) (2007) 240-246.

[6] J.H. Filho, M.H.F. Medeiros, E. Pereira, P. Helene, G.C. Isaia, High-Volume Fly Ash Concrete with and without Hydrated Lime: Chloride Diffusion Coefficient from Accelerated Test, Journal of Materials in Civil Engineering 25(3) (2013) 411-418.

[7] K. Maekawa, T. Ishida, T. Kishi, Multi-Scale Modeling of Structural Concrete: Integrated Material and Structural Mechanics, Taylor \& Francis2008.

[8] C. Pignat, P. Navi, K. Scrivener, Simulation of cement paste microstructure hydration, pore space characterization and permeability determination, Materials and Structures 38(4) (2005) 459-466. 
[9] S. Caré, Effect of temperature on porosity and on chloride diffusion in cement pastes, Construction and Building Materials 22(7) (2008) 1560-1573.

[10] H. Higashiyama, S. Manote, M. Mutsumi, T. Osamu, Characteristics of chloride diffusion and pore volume in ceramic waste aggregate mortar containing GGBS, International Journal of Geomate 11(26) (2016) 2568-2575.

[11] F.J. Luna, Á. Fernández, M.C. Alonso, The influence of curing and aging on chloride transport through ternary blended cement concrete, 2018 68(332) (2018).

[12] P. Halamickova, R.J. Detwiler, D.P. Bentz, E.J. Garboczi, Water permeability and chloride ion diffusion in portland cement mortars: Relationship to sand content and critical pore diameter, Cement and Concrete Research 25(4) (1995) 790-802.

[13] M.K. Mohammed, A.R. Dawson, N.H. Thom, Macro/micro-pore structure characteristics and the chloride penetration of self-compacting concrete incorporating different types of filler and mineral admixture, Construction and Building Materials 72 (2014) 83-93.

[14] P. Schiessl, U. Wiens, Rapid determination of chloride diffusivity in concrete with blending agents, RILEM International Workshop on Chloride Penetration into Concrete, 1995.

[15] H.-Y. Moon, H.-S. Kim, D.-S. Choi, Pore Size Distribution and Chloride Diffusivity of Concrete Containing Ground Granulated Blast Furnace Slag, Journal of the Korea Concrete Institute 16 (2004) 277-282.

[16] R.M. Ferreira, J.P. Castro-Gomes, P. Costa, R. Malheiro, Effect of metakaolin on the chloride ingress properties of concrete, KSCE Journal of Civil Engineering 20(4) (2016) 1375-1384.

[17] S. Zhang, B. Zhao, Research on chloride ion diffusivity of concrete subjected to CO2 environment, 2012.

[18] X. He, Y. Chen, B. Ma, Y. Li, H. Zhang, W. Zhang, Studies on Small Ionic Diffusivity Concrete, International Workshop on Sustainable Development and Concrete Technology, 2001.

[19] I.-S. Yoon, E. Schlangen, M. de Rooij, K. Breugel, The Effect of Cracks on Chloride Penetration into Concrete, 2007.

[20] Q. Wang, W. Sun, L. Guo, C. Gu, J. Zong, Modeling Chloride Diffusion Coefficient of Steel Fiber Reinforced Concrete under Bending Load, Advances in Civil Engineering 2018 (2018) 6.

[21] C. Fu, X. Jin, H. Ye, N. Jin, Theoretical and Experimental Investigation of Loading Effects on Chloride Diffusion in Saturated Concrete, Journal of Advanced Concrete Technology 13(1) (2015) 30-43.

[22] M. Alexander, Marine Concrete Structures, Woodhead Publishing2016.

[23] H. Du, S.D. Pang, Enhancement of barrier properties of cement mortar with graphene nanoplatelet, Cement and Concrete Research 76 (2015) 10-19.

[24] F. Torabian Isfahani, E. Redaelli, F. Lollini, W. Li, L. Bertolini, Effects of Nanosilica on Compressive Strength and Durability Properties of Concrete with Different Water to Binder 
Ratios, Advances in Materials Science and Engineering 2016 (2016) 16.

[25] D.V. Ribeiro, J.A. Labrincha, M.R. Morelli, Chloride diffusivity in red mud-ordinary portland cement concrete determined by migration tests, 14(2) (2011) 227-234.

[26] G. Sun, W. Sun, Y. Zhang, Z. Liu, C. Wang, Influence of Aggregates on Chloride Ion Diffusion Coefficient in Cement-Based Composite Materials, Journal of The Chinese Ceramic Society 39(4) (2011) 662-669.

[27] B. Touil, F. Ghomari, A. Bezzar, A. Khelidj, S. Bonnet, Effect of Temperature on Chloride Diffusion in Saturated Concrete, Materials Journal 114(5) (2017).

[28] Z. Yang, M. Tang, X. Ji, H. Hu, X. Jiang, D. Zhang, Improvement of impermeability and chemical resistance of concrete by nanocomposites, Chemical Engineering Transactions 66 (2018) 25-30.

[29] G. Jen, N. Stompinis, R. Jones, Chloride ingress in a belite-calcium sulfoaluminate cement matrix, Cement and Concrete Research 98 (2017) 130-135.

[30] M. Kikuchi, Y. Suda, T. Saeki, Evaluation for ion transport in hardened cementitious paste by oxygen diffusion and chloride diffusion, Cement Science and Concrete Technology 64 (2010) 346-353.

[31] K. Kurumisawa, T. Nawa, Electric conductivity of hardened cment paste with inorganic electrolite, Cement Science and Concrete Technology 69 (2015) 207-213.

[32] M. Mihara, M. Matsumura, A. Nagasaka, K. Torii, Study on diffusion coefficient of Cl- from EPMA and pore structure of hardened cement paste, Proceedings of the Japan Concrete Institute 29(1) (2007) 1023.

[33] S. Nwaubani, Hydration kinetics, pore characteristics and chloride ion diffusivity of blended cements, International Journal of Civil Engineering 12(3) (2014) 354-362.

[34] T. Saeki, K. Sasaki, K. Shinada, Estimation of Chloride Diffusion Coefficent of Concrete Using Mineral Admixtures, Journal of Advanced Concrete Technology 4(3) (2006) 385-394.

[35] M.R. Nokken, R.D. Hooton, Using pore parameters to estimate permeability or conductivity of concrete, Materials and Structures 41(1) (2007) 1.

[36] H. Ma, Mercury intrusion porosimetry in concrete technology: tips in measurement, pore structure parameter acquisition and application, Journal of Porous Materials 21(2) (2014) 207 215.

[37] M. N. Haque, O.A. Kayali, M.K. Gopalan, Fly Ash Reduces Harmful Chloride Ions in Concrete, Materials Journal 89(3).

[38] T. Simčič, S. Pejovnik, G. De Schutter, V. Bosiljkov, Chloride ion penetration into fly ash modified concrete during wetting-drying cycles, 2015.

[39] G.J. Osborne, Durability of Portland blast-furnace slag cement concrete, Cement and Concrete Composites 21(1) (1999) 11-21. 
[40] Y. Sakai, Relationship between air diffusivity and permeability coefficients of cementitious materials, Preprints (2018) 2018120075.

[41] Y. Sakai, Relationship between water-permeability coefficient and pore-structure indicators of cementitious materials, Preprints （2018) 2018120073.

[42] E. Nägele, The zeta-potential of cement, Cement and Concrete Research 15(3) (1985) 453462 . 